\title{
MECHANICAL BRUISING TO STRAWBERRY CAUSED BY VIBRATIONAL EQUIPMENT
}

\author{
Mayhoub, M. A. ; E. A. El-Sahhar ; A. A. Abdel-Hafez ${ }^{* *}$ and \\ M. Z. El-Attar
}

\begin{abstract}
Packaged strawberry of two cultivars grown in Egypt were submitted to vibrational equipment. During test, the accelerations at three different positions of the column of crates were measured. Vibrational energy during transportation fruits was $1200 \mathrm{~J} / \mathrm{kg}$ resulting bruise 7, 7.3\% for the two cultivars Festival and Fortuna, resp. Bruise due to vibration stress occurred in 25 and 48.2\% for Festival and Fortuna cultivars, respectively. The degree of maturity of $80-85 \%$ to less damage, where the proportion of the damage with the highest vibratory energy $(2100 \mathrm{~J} / \mathrm{kg})$, while 25\%. Exposed strawberries placed in the middle crate into the biggest damage where the percentage of damage to $50 \%$ at the end of the storage period.
\end{abstract}

Keywords: Strawberries, Transportation, Vibrational energy, Bruising

\section{INTRODUCTION}

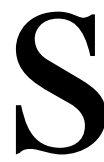

trawberry (Fragaria $x$ ananassa Duch.) is one of the most important members of the family Rosaceae. It has become one of the economic vegetable crops in Egypt and considered the main cash crop for strawberry growers in Qalyubia, Ismailia, Sharqia and Beheira governorates. Egypt strawberry exported 301,488 tons in 2012 valued \$ 59 million.

Fruits of strawberry are highly sensible to mechanical damage. Impacts, friction, and compression occur during harvest, postharvest handling and transportation (Snowdon, 1990).

Mechanical injuries are responsible for considerable decay of fresh fruits and vegetables. Produce discarded because of damage in the chain between the grower and the consumer is estimated at around $30-40 \%$ (Peleg \& Hinga, 1986).

\footnotetext{
*Agricultural Engineering Department, Faculty of Agriculture, Ain Shams University

*** Horticulture Department, Faculty of Agriculture, Ain Shams University
} 
Mechanical stresses occur during picking and packaging. Various studies have been carried out to assess the effects of these stresses on fresh fruits (Bartram et al., 1983; Bollen \& De La Rue, 1990; Brown et al., 1987; Burton et al., 1989; Peleg, 1985). During the transportation, the damage of fruits manifests itself in two aspects. One is caused by the impact, such damage results into the plastic deformation to mainly bring the present fruits injury. The other is the acceleration due to vibration effects caused by repeated low-stress fatigue damage, which usually results in fruit organizational structure changes, then the delay caused fruit injury. Therefore, study on the vibration load caused injury factors have very important value (Barchi et al., 2002)

This work reports the first results of an evaluation of the qualitative decay of these fruits due to damage of repetitive load. The aim of the study were evaluate strawberry quality due to vibration effects caused by repeated low-stress fatigue damage.

\section{MATERIALS AND METHODS}

The strawberry fruits (Fragaria $\mathbf{x}$ ananassa Duch, Cv.) 'Festival' and 'Fortuna', strawberries obtained from privet farm in spring season 2015 (Badr Center-El-Beheira Governorate-Egypt). Festival is hybridized variety by University of Florida (Chandler et al., 2000). Fortuna (named Florida Radiance in North America) released by the University of Florida in 2008 (Chandler et al., 2009). The strawberries grown in double rows on raised beds covered with black plastic mulch, with drip irrigation system. The strawberry fruits packed into a container plastic "punnet" with dimensions of $200 * 100 * 60 \mathrm{~mm}$ with $250 \mathrm{~g}$ net weight. Ten punnets put into the crate-packaging box with dimensions of $600 * 400 * 80 \mathrm{~mm}$.

\section{Vibration measurement}

The accelerometer firmly mounted on the upper strawberry box was used for the measurement of vibration 3-axis along with lateral the truck-bed and vertically across the strawberry boxes during the laboratory vibration simulation tests and the actual road transportation tests, vibration data were collected at a sampling frequency of $50 \mathrm{~Hz}$. Measuring time was about 300 to 600 seconds. The data stored in the computer, then analyzed 
using mathematical software. Welch method was used for estimating the Power Spectral Density (PSD).

$$
\text { Power Density }=\frac{4 *\left(\operatorname{Re}^{2}+\mathrm{Im}^{2}\right)}{n^{2}} \ldots \ldots \ldots . .(1)
$$

\section{Vibrational equipment}

A prototype of the experiment set to test vibration parameters affected on fruits during handling, designed and fabricated in the Agricultural Engineering Department Workshop, Ain-Shams Univ. A three phase's electrical motor of $0.75 \mathrm{~kW}$ "China", $380 \mathrm{~V}$, and 1450-rpm rotational speed powered the set mechanism. The motor and entire elements assembled in a frame of angle-section steel bars. Frame dimensions and constructions are illustrated in Figs. 1 and 2. Motor rotations was controlled through $1.5 \mathrm{~kW}$ inverter. Transmitted rotary motion converted to the vibratory motion of a crank mechanism. A vibrated bar was used to transmit shaking action from the crank to fruit box. The fruit plat form made from wood 800X500X20 mm.

\section{Measuring vibration device}

Tri-axis digital output accelerometer-microelectro-mechanical systems (MEMS) for measuring acceleration along its $\mathrm{X}, \mathrm{Y}$ and $\mathrm{Z}$ axis, through an analog to digital converter and a digital Low-Pass filter. The accelerometer sensitivity ranges of $\pm 0.0039 \mathrm{~m} . \mathrm{s}^{-2}$. The collected (recorded) data were analyzed a smart phone Android programming plot form application.

\section{Damage evaluation}

Each fruit after the vibration treatment submerged in fluorescence liquid to fluorite under UV light exposing damaged area. An image processing tech. was used to estimate surface damage on four location of strawberry fruit. The fruit image captured automatically by a digital camera (BenQ, China) shoots the fruit located on quad position rotational platform. Synchronized with the image capturing system to scan the fruit surface area in four frames (Fig. 3). The bruising area estimated by using ENVI program (Version 5.1 classic) as follows: 

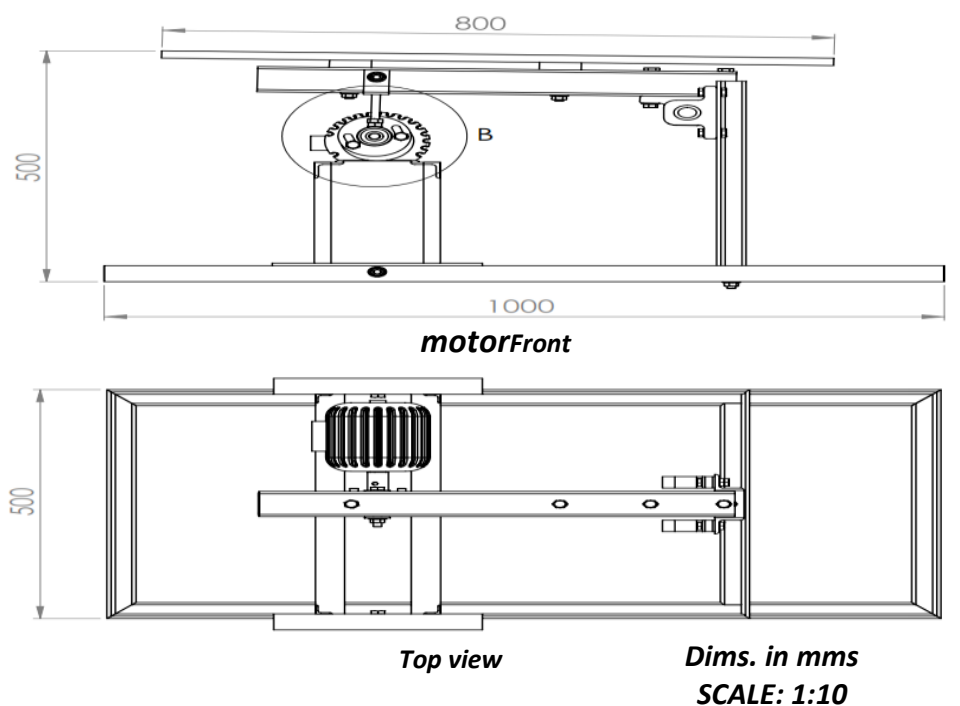

Fig. 1: Vibrational equipment views.

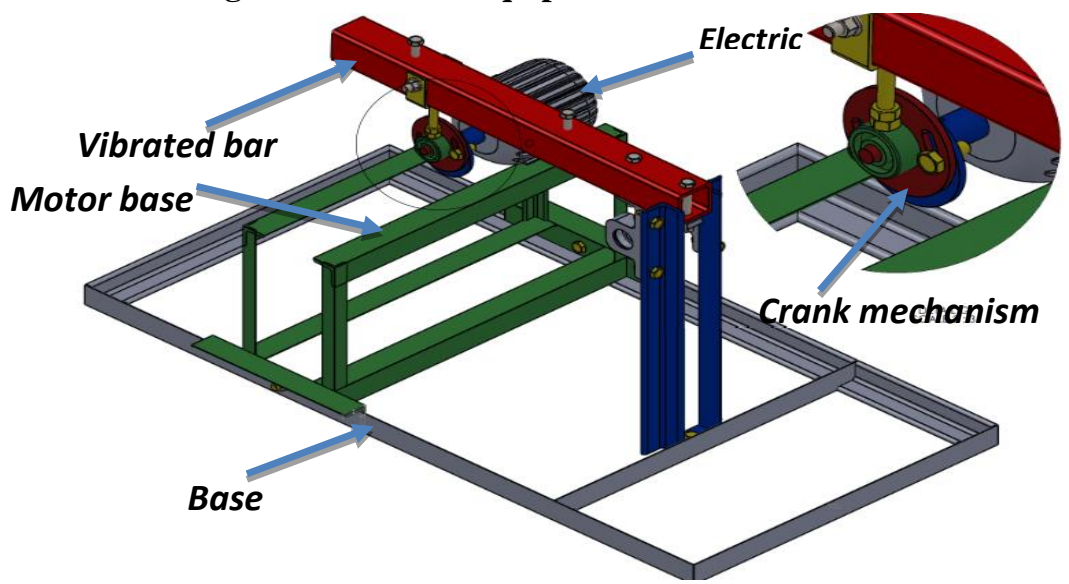

Fig. 2: All parts of mechanism as assembly.

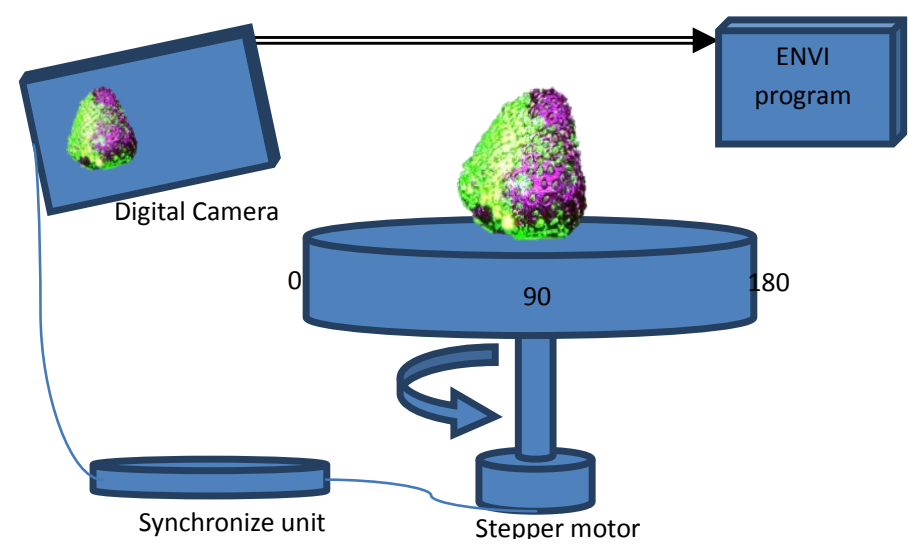

Fig. 3: Mechanical damage inspector. 
1- Regions of interest (ROIs) are portions of images, either selected graphically or selected by other means such as a threshold, as shown in Fig. 4-b.

1- $\quad$ Use Build Mask to build image masks from specific data values, as shown in Fig.4-c, in this step can calculate the area in pixel by using compute statistics.

2- $\quad$ Use Apply Mask to permanently apply a mask to an image, giving that the masked out value is what specified, as shown in Fig.4-d.

3- $\quad$ Band Math is dialog to define bands or files used as input, to call a user Band Math function, and to write the result to a file or memory. The Band Math function accesses data spatially by mapping variables to bands or files, as shown in Fig.4-e, $\mathbf{f}$ and $\mathbf{g}$.

4- ISODATA unsupervised classification calculates class means evenly distributed in the data space, then iteratively clusters the remaining pixels using minimum distance techniques. (Tou, and Gonzalez, 1974), as shown in Fig.4-h.

5- $\quad$ Use Combine Classes to selectively merge classes in classified images as shown in Fig.4-i.

6- ENVI Classic polygon vector layers (EVF files). The classification

7- $\quad$ Images will have a vector layer for each selected class, as shown in Fig.4-j.

8- $\quad$ Selected class containing the damage in fruit, then saves in new vector layer, as shown in Fig.4-k.

9- Convert separate damage vector to raster for calculating its area by using Subset Data via ROIs to subset data into a rectangle that contains the selected ROIs.The rectangle is the smallest rectangle that will fit the ROI. Can masked the pixels in the rectangle that do not come inside the ROI, as shown in Fig.4-l, in this step can calculate the area in pixel by using compute statistics. To determine the fruit bruising percent was used the following equation (2).

Percent of fruit bruising $(\%)=\frac{A_{b}}{A_{f}} \times 100$

Where: $\boldsymbol{A}_{\boldsymbol{b}}$ is bruising area in $\mathbf{m m}^{\mathbf{2}}$ and $\boldsymbol{A}_{\boldsymbol{f}}$ is the total surface area of the fruit in $\mathbf{m m}^{\mathbf{2}}$. 


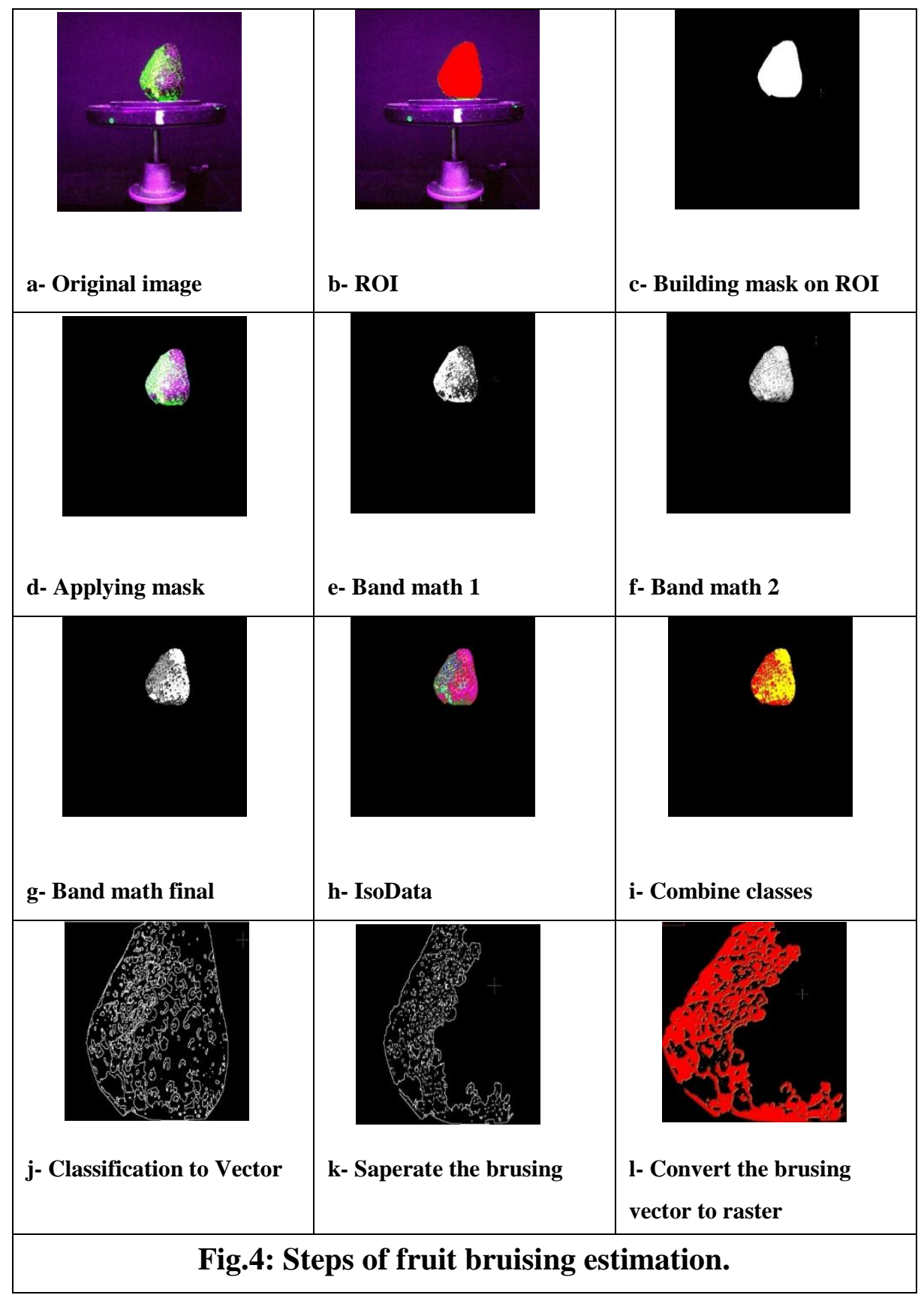

\section{Stack of strawberry columns}

The transmission of the vibration acceleration through strawberry boxes stacked on the moving truck simulated with twenty single strawberry columns (labeled 1S to 20S) stacked on a laboratory vibrational set each containing one layer of strawberries. 


\section{RESULTS AND DISCUSSION}

\section{1-Effect of vibration energy on bruise percent}

The values in Fig. 5 were obtained at accumulating vibrational energies of the vibrational table from 1200 to $2100 \mathrm{~J} / \mathrm{kg}$. Throughout this range, greater vibration energy increased the percentage of fruit bruise. The increase in bruise percent values at higher vibrational energies was due to increase the friction between fruit surfaces during the transporting process. In addition, a fatigue stress causes the microfibrils to straighten out and snap (Holt and Schoorl, 1982). Therefore, since more energy is dissipated in the breaking of microfibrils.

\section{2-Effect of strawberry cultivar on bruise percent}

The fruit bruise percentage is also affected with strawberry cultivar, as shown in Fig. 5. The bruise percent increased from 11.3 to $25 \%$ for Festival cultivar and from 15.2 to $42.8 \%$ for Fortuna cultivar by increasing the vibrational energy from 1200 to $2100 \mathrm{~J} / \mathrm{kg}$ respectively at $80-85 \%$ fruit ripening degree. Decrease in fruit percent for Festival cultivar is due to decreased moisture content of fruit and increased both fruit elasticity and firmness.

\section{3-Effect of fruit ripening degree on bruise percent}

The effect of fruit ripening degree on the bruise percent is shown in Fig. 5. The bruise percentages increased from 25 to 34 and $42 \%$ for Festival cultivar and, from 42.8 to 53 and $65 \%$ by increasing fruit ripening degree from $80-85$ to $85-90$ and $90-95 \%$ respectively at $2100 \mathrm{~J} / \mathrm{kg}$ vibrational energy. Increase in fruit bruise percentage of higher ripening degrees may be related to the conformation of the cell wall and due to increase, the cells bursting under low fatigue.

\section{4- Effect of storage period on bruise percent}

The results showed that the percentages of fruit bruises are related to the storage period (Fig. 6). Therefore, the percent of fruit bruise increased as the storage period increased for both Festival and Fortuna cultivars at all different levels of vibrational energy. The bruise percent increase from 10 to 18 to 30 and $37 \%$ for Festival cultivar and, from 11 to 25 to 42 and $52 \%$ for Fortuna cultivar by increasing the vibrational energy resp. at 50 hours' time after treatment. This may be attributed to the fruits became fully ripened and consequently the cells have weaker walls and damaged 
cell losses moisture quickly, exposes the beside cells to attack of the fungus.
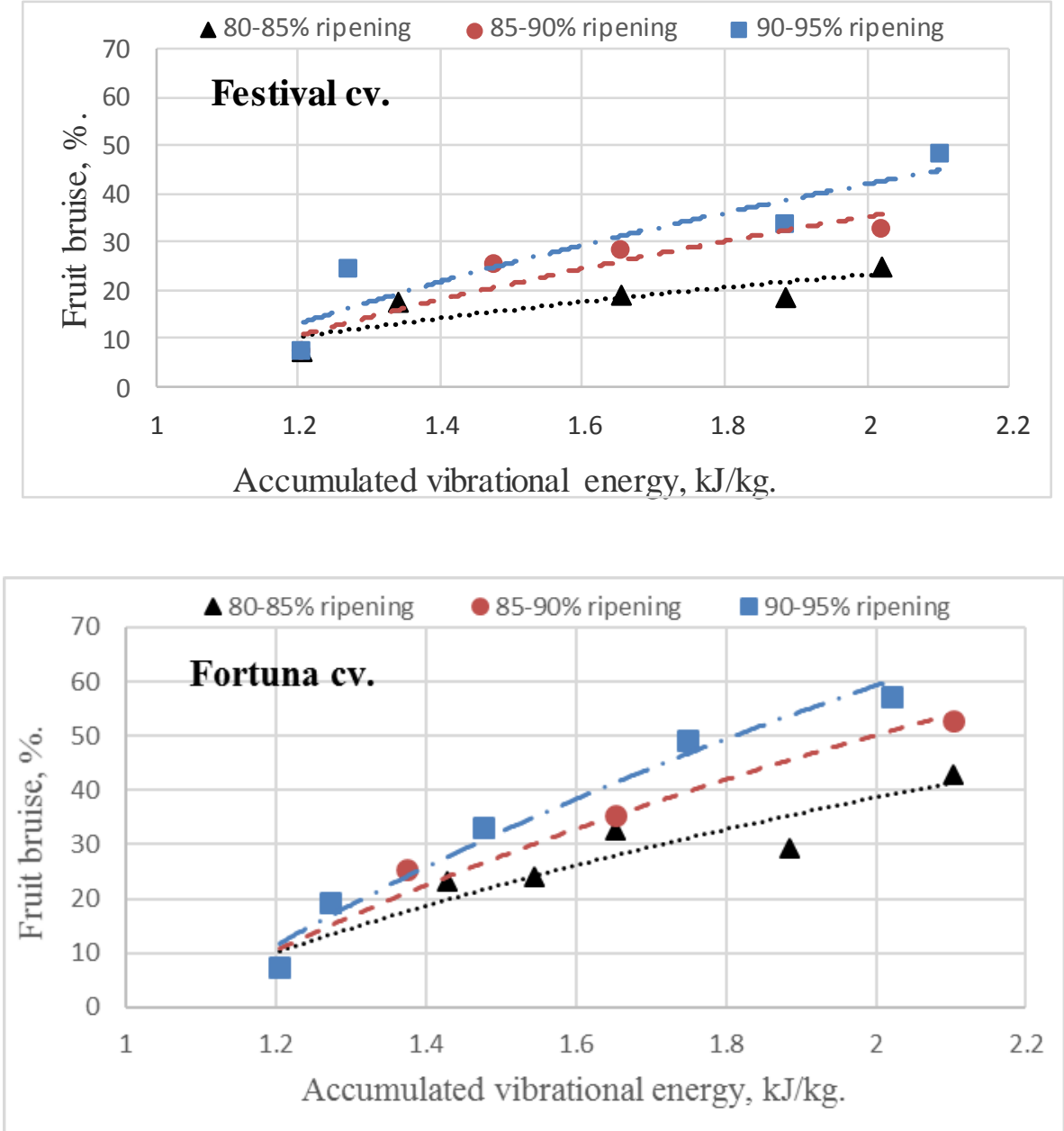

Fig. 5: Effect of energy spectral density on the fruit bruise at different fruit ripening degrees.

\section{5- Effect of fruit box height on bruise percent}

The effect of the fruit box height on the vibrational table (which represents the box position on the vehicle-bed) on percentages of fruit bruise is shown in Fig. 7. Bruise percent value varied from low values at the top and bottom positions to high values at the middle position for both Festival and Fortuna cultivars during the storage period (Fig. 7). 
Although, there is a high vibration in top boxes, the middle box received twice as much damage as the top and bottom boxes. This can be attributed to the resonant frequency of the column occurred in a range where peaks of PSD were observed at the middle position on to the vibrational table. Moreover, the decrease in bruise percent at top box is attributed to the increased of lateral vibrations which reduce the vertical vibration effects.
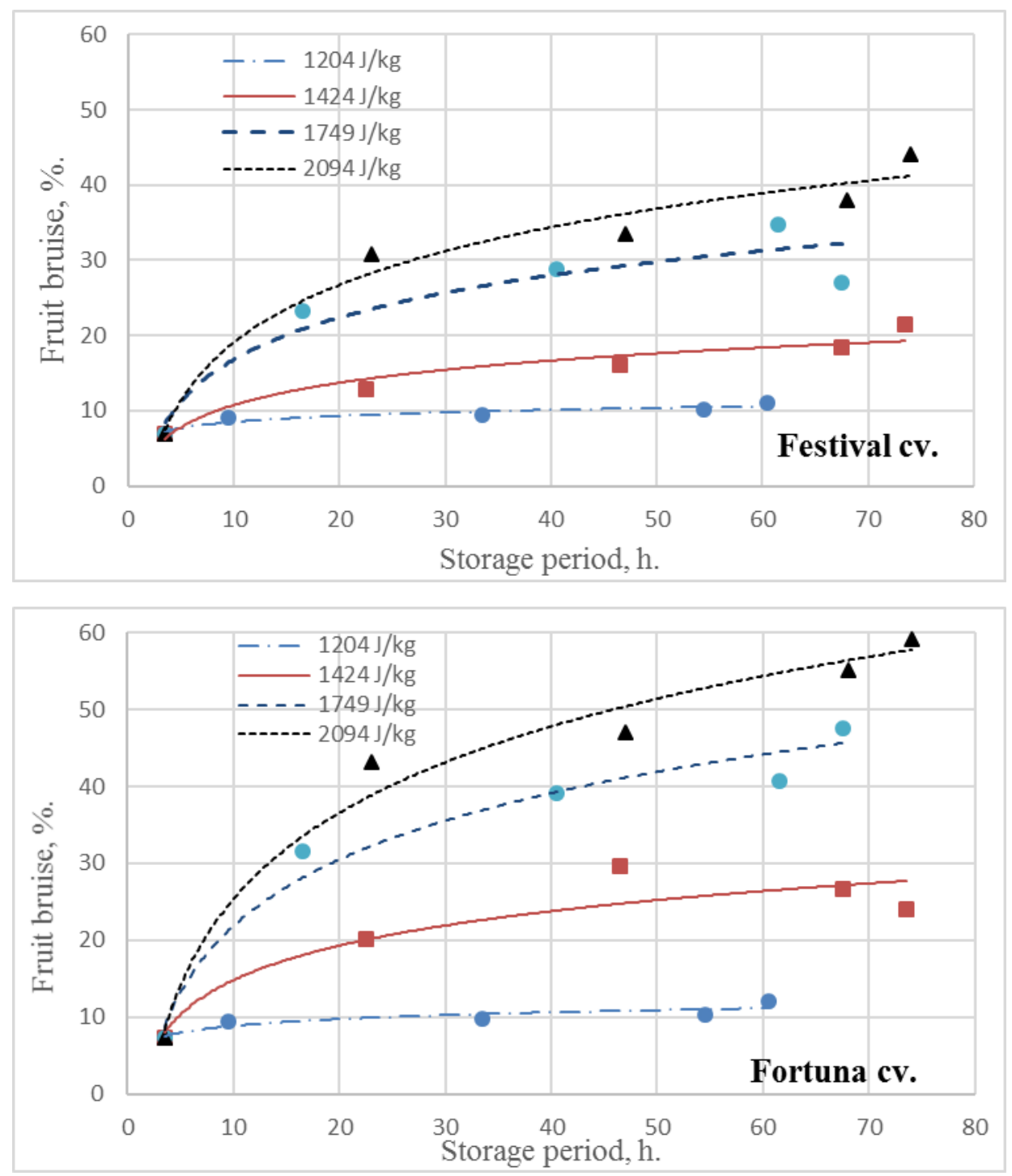

Fig. 6: Effect of storage period after the vibration treatment on the fruit bruise at different energy spectral densities. 

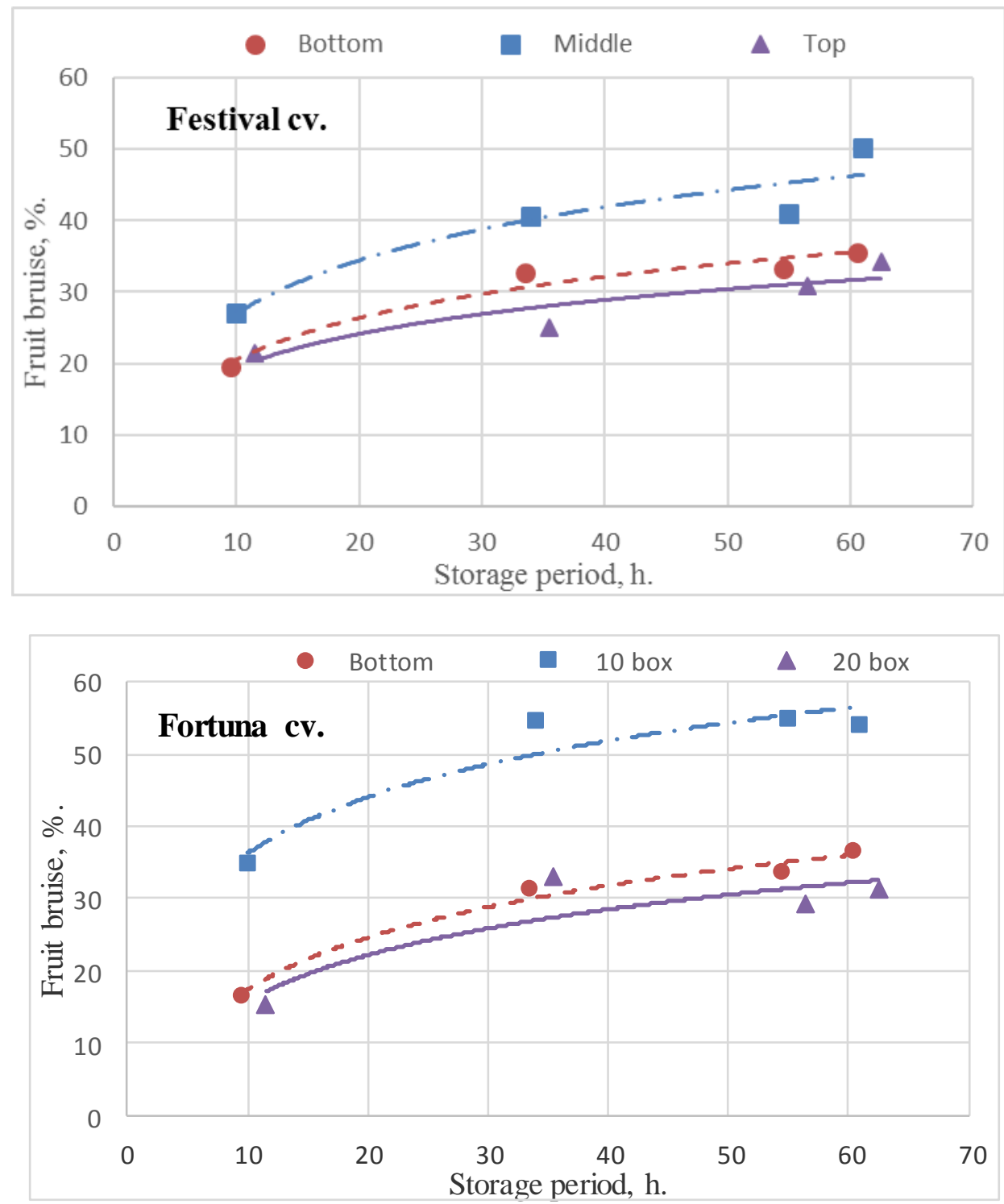

Fig. 7: Effect of storage period after the vibration treatment on the fruit bruise at different box positions on vibrational table.

\section{SUMMERY AND CONCLUSIONS}

1- took transfer of the fruits used in the experiment operations for three hours and was energy vibrating her up and got to the lab in $1204 \mathrm{~J} / \mathrm{kg}$, resulting in a ratio of bruising of 7, 7.3\% for the two cultivars Festival and Fortuna, respectively . 
2- The proportion of the damage in the fruits when stored at a temperature of $21{ }^{\circ} \mathrm{C}$ for 6 hours, reaching 9.04, 9.34\% for the two cultivars Festival and Fortuna, respectively .

3- Experienced the fruits of the degree of maturity of $80-85 \%$ to less damage, where the proportion of the damage with the highest vibratory energy (2094 J/kg), while $25 \%$ were in the fruits of the degree of maturity of the Supreme 32, $48.2 \%$, respectively, for each of the $85-90 \%$ and $90-$ $95 \%$.

4- Whenever exposed fruits to the highest vibratory energy the higher the proportion of the damage by the terms of the proportion of the damage has increased 11 to $21 \%$ increase in energy from 1204 to $1424 \mathrm{~J} / \mathrm{kg}$.

5- Exposed strawberries placed in the middle crate into the biggest damage where the percentage of damage to $50 \%$ at the end of the storage period (61 hours) and that the class Festival.

\section{REFERENCES}

Barchi, G. L. A. Berardinelli, A. Guarnieri, L. Ragni, C. Totaro Fila, (2002).

Damage to Loquats by Vibration-simulating Intra-state Transport. Biosystems Engineering, vol.82, p.305-312.

Bartram R K; Fountain J; Olsen K; O'Rourke D (1983). Washington State apple condition at retail (eating quality). Proceedings of Washington State Horticulture Association, 79, 36-46

Bollen A F; De La Rue B T (1990). Handling impacts for kiwifruit, Asian pears and apples. ASAE Paper No. 90-6005

Brown G K; Burton CL; Sargent S A; Schulte Pason N L; Timm E J; Marshall D E (1987). Apple packing line damage assessment. ASAE Paper No. 87-6515

Burton CL; Brown G K; Shulte Pason N L; Timm E J (1989). Apple bruising related to picking and hauling impacts. ASAE Paper No. 89-6049

Chandler, C. K., B. M. Santos, N. A. Peres, C. Joquand, A. Plotto, and C. A. Sims, 2009. 'Florida Radiance' Strawberry." HortScience 44: 1769-1770. 
Chandler C. K., D. E. Legard, D. D. Duningan, T. E. Crocker and C. A. Sims. (2000). 'Strawberry Festival' Strawberry. HortScience 35: 13661367.

Holt, J. E. and D. Schoorl, (1982). Strawberry bruising and energy dissipation. Journal of Texture Studies, 13 (3): 349-357.

Peleg K; and S. Hinga (1986). Simulation of vibration damage in produce transportation. Transactions of the ASAE, 29(2), 633-641

Peleg K., (1985). Produce Handling Packaging and Distribution. AVI Publishing Company, Westport

Snowdon, A. L. (1990). A color atlas of post-harvest diseases and disorders of fruits and vegetables. General introduction and fruits (vol. 1). London, England: Wolfe Publishing, p. 250.

Tou, J. T. and R. C. Gonzalez, (1974). Pattern Recognition Principles, AddisonWesley Publishing Company, Reading, Massachusetts.

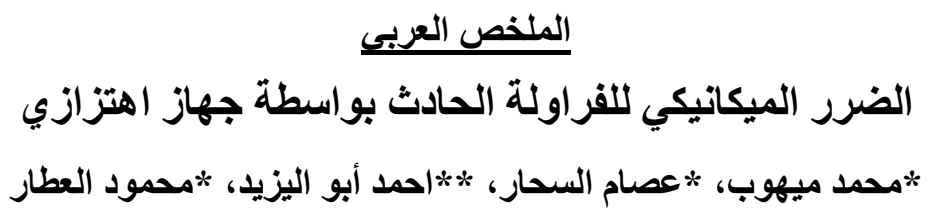

تم معاملة صنفين من ثمار الفراولة المعدة للتصدير بجهاز اهتزازي، قيست العجلة عند ثلاث

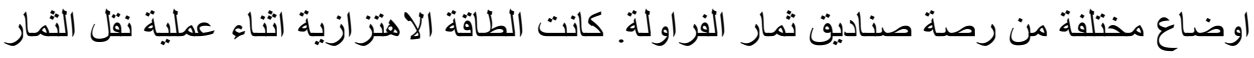

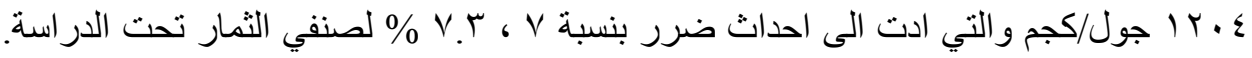

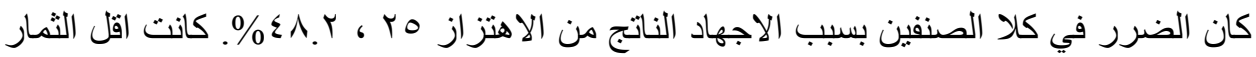

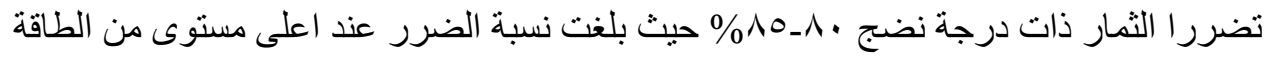

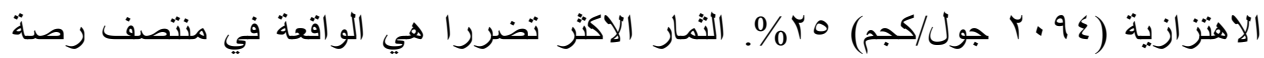

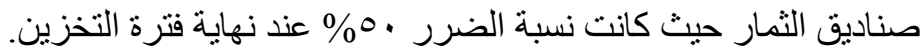

